\title{
The effect of cardiopulmonary bypass prime volume on the need for blood transfusion after pediatric cardiac surgery
}

\author{
Marc E. Richmond, MD, MS, ${ }^{\mathrm{a}}$ Kevin Charette, CCP, ${ }^{\mathrm{b}}$ Jonathan M. Chen, MD, \\ Jan M. Quaegebeur, MD, ${ }^{\mathrm{b}}$ and Emile Bacha, $\mathrm{MD}^{\mathrm{b}}$
}

\begin{abstract}
Objective: There is increasing awareness that erythrocyte transfusions after pediatric cardiac surgery have deleterious effects. Despite reports of decreased transfusion requirements associated with smaller cardiopulmonary bypass circuits, the relationship between circuit prime volume and need for transfusion has not been systematically examined.
\end{abstract}

\begin{abstract}
Methods: Pediatric patients at our institution who underwent cardiopulmonary bypass between January 2005 and December 2010 were reviewed. Demographics, intraoperative data, and transfusion of packed red blood cells were retrospectively recorded. Cardiopulmonary bypass prime volume was indexed by patient body surface area. Logistic regression analysis was used to correlate these variables with need for transfusion.

Results: In the perioperative period, 1912 patients received transfusions and $266 \mathrm{did}$ not. In univariate analysis, indexed prime volume was a significant predictor of transfusion (odds ratio, 1.007; $P<.001$ ). Other significant variables in univariate analysis included age, surgeon, Risk Adjustment for Congenital Heart Surgery 1 (RACHS-1) category, preoperative hemoglobin, total bypass time, aortic crossclamp time, use and duration of deep hypothermic circulatory arrest, lowest body core temperature, and cardiopulmonary bypass flow rate. Previous cardiac surgery was not a significant predictor. In multivariable analysis controlling for RACHS- 1 category, surgeon, minimal core body temperature, and preoperative hemoglobin, indexed prime volume remained an independent predictor of transfusion (odds ratio, 1.006; 95\% confidence interval, 1.005-1.007, $P<.001$ ).

Conclusions: Perioperative need for transfusion in pediatric cardiac surgical patients is independently related to the prime volume of the cardiopulmonary bypass circuit. It therefore seems prudent to minimize circuit prime volumes to avoid unnecessary use of blood products. (J Thorac Cardiovasc Surg 2013;145:1058-64)
\end{abstract}

Recent publications have shown that the need for a blood transfusion in the postoperative period may increase the duration of mechanical ventilation and hospitalization in children undergoing surgical repair of congenital heart disease. ${ }^{1,2}$ Furthermore, even if donor blood is safe from infections, there still remain significant morbidities related to the use of donor packed red blood cells (pRBCs), including anaphylactoid transfusion reactions. Despite the almost universal agreement that avoidance of blood products is desirable, there has not been a recent evaluation of factors contributing to the use of blood transfusions in this population. In the past decade, advances in cardiopulmonary bypass (CPB) circuits have resulted in the ability to have smaller prime volumes, decreasing the patient's initial intraoperative exposure to

From the Division of Pediatric Cardiology, ${ }^{a}$ Department of Pediatrics, and the Division of Pediatric and Congenital Cardiac Surgery, ${ }^{b}$ Department of Surgery, Columbia University College of Physicians and Surgeons, New York, NY.

Disclosures: Authors have nothing to disclose with regard to commercial support.

Received for publication Jan 24, 2012; revisions received May 22, 2012; accepted for publication July 10, 2012; available ahead of print Aug 6, 2012.

Address for reprints: Marc E. Richmond, MD, MS, Division of Pediatric Cardiology, 3959 Broadway, Babies Hospital 2-North, New York, NY 10032. (E-mail: mr2306@columbia.edu).

0022-5223/\$36.00

Copyright (c) 2013 by The American Association for Thoracic Surgery

http://dx.doi.org/10.1016/j.jtcvs.2012.07.016 donor blood. The decreased prime volume may also contribute to improved outcomes, especially in smaller infants and children.

This study was designed to examine the factors that lead to the need for transfusions of $\mathrm{pRBCs}$ in the perioperative period and to examine whether CPB prime volume affects the risk of receiving a $\mathrm{pRBC}$ transfusion in the perioperative period in children undergoing surgery with $\mathrm{CPB}$ for congenital heart disease.

\section{MATERIALS AND METHODS \\ Study Population}

This study was approved by the institutional review board of Columbia University. All patients younger than 18 years who underwent cardiac surgery with CPB at the Morgan Stanley Children's Hospital of New York between January 1, 2005, and December 31, 2010, were considered for inclusion. Patients undergoing ventricular assist device implantation, repair of cardiac trauma, or reoperation for hemorrhage were excluded, because these patients differ dramatically from other cardiac surgical patients in transfusion strategy. Furthermore, patients undergoing heart transplant were excluded because immunologic factors may play a role in whether they receive a transfusion.

\section{Study Design}

Demographic, surgical, and perfusion related data were collected from a prospectively collected institutional database. These data included sex, age at surgery, surgeon, body surface area (BSA) in square meters (as calculated according to the Haycock formula), surgical procedure, anatomic 


$$
\begin{array}{ll}
\text { Abbreviations and Acronyms } \\
\text { BSA } & =\text { body surface area } \\
\text { CPB } & =\text { cardiopulmonary bypass } \\
\text { DHCA } & =\text { deep hypothermic circulatory arrest } \\
\text { MUF } & =\text { modified ultrafiltration } \\
\text { pRBCs } & =\text { packed red blood cells } \\
\text { RACHS- } & =\text { Risk Adjustment for Congenital } \\
& \text { Heart Surgery } 1
\end{array}
$$

diagnosis, number of previous cardiac surgical procedures, number of previous cardiac surgical procedures with $\mathrm{CPB}$, preoperative hemoglobin in grams per deciliter, CPB circuit prime volume in milliliters, total CPB time in minutes, aortic crossclamp time in minutes, deep hypothermic circulatory arrest (DHCA) time in minutes, minimal core body temperature in ${ }^{\circ} \mathrm{C}$, maximum CPB circuit flow rate in liters per minute, hospital stay in days, and mortality. A separate clinical database was reviewed to assess whether each patient had received any transfusions with pRBCs in the perioperative period, defined as the time from when the patient arrived in the operating room (postoperative day 0 ) through postoperative day 6 (or hospital discharge if sooner). Surgical procedures were risk categorized according to the Risk Adjustment for Congenital Heart Surgery 1 (RACHS-1) method. ${ }^{3}$ The RACHS-1 method uses 6 categories of surgical risk, with category 1 having the lowest risk and 6 the highest. Specific surgical procedures are assigned to each category, so those surgical procedures that did not fit into one of the RACHS-1 categories were labeled as "none." Both CPB circuit prime volume and maximum CPB circuit flow rate were indexed for BSA, resulting in the variables of indexed prime volume in milliliters per square meter and indexed flow rate in liters per minute per square meter. For analysis purposes, patients were divided into 2 groups, those who received any volume of $\mathrm{pRBC}$ transfusion in the perioperative period and those who did not.

\section{Statistical Analysis}

All continuous variables were examined for normality. Normal variables are expressed as mean $\pm \mathrm{SD}$; nonnormal variables are expressed as median with either range or interquartile range. Factors were compared between the transfusion groups with the Student $t$ test, Mann-Whitney U test, or $\chi^{2}$ analysis as appropriate. Univariate logistic regression was used to evaluate the association between each variable and the outcome of pRBC transfusion. A multivariable model was then created to evaluate the association of indexed prime volume to the outcome of $\mathrm{pRBC}$ transfusion after controlling for other factors. All variables with a $P$ value less than 0.1 in the univariate analysis were considered for inclusion in the multivariable model, and surgeon was chosen a priori to be in the model regardless of statistical considerations. Other candidate variables were not included in the final model if (1) they were not significant predictors of outcome and (2) there was no appreciable effect on the remaining variables whether or not they were included in the model (ie, a $<10 \%$ change in the $\beta$ coefficient). All statistical tests were 2-sided. Statistical analyses were performed with SPSS Statistics 18 for Windows software (IBM Corporation, Armonk, NY).

\section{RESULTS}

\section{Population Demographics}

The total number of patients meeting inclusion and exclusion criteria for the study was 2268. Of these, 90 $(4 \%)$ were further excluded for missing data required for the calculation of the primary predictor variable of indexed prime volume (height, weight, BSA, or prime volume). This left 2178 patients for inclusion and analysis. The median age at surgery was 6 months (range, 1 day-17.9 years; interquartile range, 25 days- 2.8 years), and $58.3 \%$ of the patients were male. Weight at surgery ranged from $1.1 \mathrm{~kg}$ to $151 \mathrm{~kg}$ (median, $6.2 \mathrm{~kg}$; interquartile range, $3.6-13 \mathrm{~kg}$ ). Simple structural heart disease was the indication for surgery in $44.1 \%$ of cases, whereas $22.8 \%$ had cyanotic heart disease, $5.1 \%$ had complex acyanotic heart disease, and $26.4 \%$ had single-ventricle physiology. In total, 652 patients $(30 \%)$ had previously undergone cardiac surgery, with 266 having more than 1 previous operation. Of these, only 83 patients had previously undergone surgery that did not involve CPB.

\section{Operative Characteristics}

The most common surgical procedure performed was ventricular septal defect closure (9.6\%), with total cavopulmonary connection $(8.8 \%)$, tetralogy of Fallot repair $(8.3 \%)$, and superior cavopulmonary anastomosis $(8 \%)$ the second, third, and fourth most frequent procedures, respectively. The vast majority of procedures were classified as RACHS1 category $2(37.5 \%)$ or category $3(36.4 \%)$. RACHS- 1 category 1 procedures only accounted for $7 \%$ of all procedures, and category 4 accounted for $11.1 \%$. Only 1 procedure was classified as RACHS- 1 category 5 , and $6 \%$ (131) were classified as category 6 . There were 42 procedures $(2.2 \%)$ that were not classifiable under the RACHS-1 method, most of which were repairs of pulmonary vein stenosis. Only 16 patients did not have a measured hemoglobin value within the 2 -week period before surgery. The mean preoperative hemoglobin value in the remaining 2162 patients $(99 \%)$ was $13.6 \pm 2.3 \mathrm{~g} / \mathrm{dL}$. Absolute CPB circuit prime volume ranged from 27 to $1400 \mathrm{~mL}$. When indexed for patient BSA, the mean prime volume was $780 \pm 300 \mathrm{~mL} / \mathrm{m}^{2}$. The mean CPB time was $104 \pm 49$ minutes, with a mean indexed flow rate of $2.3 \pm 0.7 \mathrm{~L} /\left(\mathrm{min} / \mathrm{m}^{2}\right)$. Aortic crossclamp with cardioplegia was used in $86.8 \%$ of procedures, with a mean crossclamp time of $50.6 \pm 30.2$ minutes. DHCA was used in $32.6 \%$ of cases, with a mean arrest time of $31.4 \pm 17.8$ minutes. The mean minimal core body temperature was $31.3^{\circ} \mathrm{C} \pm 3.8^{\circ} \mathrm{C}$ for patients in whom DHCA was not used and $18.8^{\circ} \mathrm{C} \pm 2.4^{\circ} \mathrm{C}$ in those in whom it was.

\section{Group Comparisons}

When the total study population was divided into those who required pRBC transfusion $(\mathrm{n}=1912)$ and those who did not $(\mathrm{n}=266)$, differences in demographic and intraoperative factors became apparent (Table 1). Specifically, patients who did not require pRBC transfusions were significantly older ( 5.7 vs 0.4 years; $P<.001$ ), heavier $(21.2$ vs $5.5 \mathrm{~kg} ; P<.001)$, and larger in BSA ( 0.8 vs $\left.0.31 \mathrm{~m}^{2} ; P<.001\right)$. Patients who did not require pRBC transfusion also tended to have a lower RACHS-1 
TABLE 1. Demographic characteristics and clinical outcomes of patients, as divided between those who received at least 1 packed red blood cell transfusion and those who did not

\begin{tabular}{|c|c|c|c|}
\hline & No transfusion $(n=266)$ & Transfusion $(n=1912)$ & $P$ value \\
\hline Age in (y, median and range) & $5.7(1 \mathrm{~d}-17.7 \mathrm{y})$ & $0.4(1 \mathrm{~d}-17.9 \mathrm{y})$ & $<.001$ \\
\hline Weight (kg, median and range) & $21.2(1.8-150)$ & $5.5(1.1-151)$ & $<.001$ \\
\hline BSA $\left(\mathrm{m}^{2}\right.$, median and range $)$ & $0.8(0.15-2.32)$ & $0.31(0.11-2.52)$ & $<.001$ \\
\hline Diagnosis (no.) & & & $<.001$ \\
\hline Simple structural heart disease & $193(72.6 \%)$ & $767(40.1 \%)$ & \\
\hline Complex acyanotic disease & $1(0.4 \%)$ & $109(5.7 \%)$ & \\
\hline Cyanotic heart disease & $21(7.9 \%)$ & $476(24.9 \%)$ & \\
\hline Single ventricle & $49(18.4 \%)$ & $525(27.4 \%)$ & \\
\hline Other & $2(0.8 \%)$ & $35(1.8 \%)$ & \\
\hline RACHS-1 category (no.) & & & $<.001$ \\
\hline 1 & $77(28.9 \%)$ & $75(3.9 \%)$ & \\
\hline 2 & $73(27.4 \%)$ & $744(38.9 \%)$ & \\
\hline 3 & $112(42.1 \%)$ & $681(35.6 \%)$ & \\
\hline 4 & $3(1.1 \%)$ & $239(12.5 \%)$ & \\
\hline 5 & $0(0 \%)$ & $1(0.1 \%)$ & \\
\hline 6 & $1(0.4 \%)$ & $130(6.8 \%)$ & \\
\hline None & $0(0 \%)$ & $42(2.2 \%)$ & \\
\hline Previous cardiac surgery (no.) & $80(30.1 \%)$ & $572(29.9 \%)$ & .96 \\
\hline Preoperative hemoglobin ( $\mathrm{g} / \mathrm{dL}$, mean $\pm \mathrm{SD}$ ) & $14.3 \pm 2.2(\mathrm{n}=261)$ & $13.5 \pm 2.3(\mathrm{n}=1901)$ & $<.001$ \\
\hline Previous surgery with CPB (no.) & $72(27.1 \%)$ & $497(26 \%)$ & .71 \\
\hline Prime volume (indexed to BSA as $\mathrm{mL} / \mathrm{m}^{2}$, mean $\pm \mathrm{SD}$ ) & $444 \pm 207$ & $826 \pm 279$ & $<.001$ \\
\hline $\mathrm{CPB}$ time (min, mean $\pm \mathrm{SD})$ & $80 \pm 45$ & $107 \pm 48$ & $<.001$ \\
\hline Flow rate (indexed BSA as $\mathrm{L} /\left[\mathrm{min} / \mathrm{m}^{2}\right]$, mean $\pm \mathrm{SD}$ ) & $2.25 \pm 0.35$ & $2.35 \pm 0.77$ & .03 \\
\hline Crossclamp use (no.) & $230(86.5 \%)$ & $1660(86.8 \%)$ & .87 \\
\hline Crossclamp time (min, mean $\pm \mathrm{SD}$ ) & $40 \pm 31$ & $52 \pm 30$ & $<.001$ \\
\hline DHCA use (no.) & $14(5.3 \%)$ & $696(36.4 \%)$ & $<.001$ \\
\hline DHCA time (min, median and range) & $21(12-45)$ & $33(2-144)$ & .005 \\
\hline Hospital stay (d, median with interquartile range) & $4.8(3.6-7.0)$ & $7.5(5-13)$ & $<.001$ \\
\hline Mortality (no.) & $1(0.4 \%)$ & $86(4.5 \%)$ & .001 \\
\hline
\end{tabular}

$B S A$, Body surface area; $C P B$, cardiopulmonary bypass; $D H C A$, deep hypothermic circulatory arrest; RACHS- 1 , Risk Adjustment for Congenital Heart Surgery 1 .

classification, with a larger percentage being in RACHS-1 category 1 and fewer being in RACHS-1 categories 4, 5, or 6. All patients who were not classifiable by the RACHS-1 system required pRBC transfusions. Surprisingly, there were no differences in the proportions of patients who had previous cardiac procedures or previous procedures requiring CPB. The mean preoperative hemoglobin value was significantly higher in the group who did not require transfusion $(14.3 \pm 2.2$ vs $13.5 \pm 2.3 \mathrm{~g} / \mathrm{dL}$; $P<.001)$. The mean indexed CPB prime volume was also lower in the group that did not receive $\mathrm{pRBC}$ transfusions (444 \pm 207 vs $\left.826 \pm 279 \mathrm{~mL} / \mathrm{m}^{2} ; P<.001\right)$, as was the mean total $\mathrm{CPB}$ time $(80 \pm 45$ vs $107 \pm 48$ minutes; $P<.001)$. There was also a statistically significant but small difference in the mean indexed flow rates, with patients who required blood transfusion having a slightly higher flow rate $\left(2.35 \pm 0.77 \mathrm{~L} /\left[\mathrm{min} / \mathrm{m}^{2}\right]\right)$ than those who $\mathrm{did}$ not $\left(2.25 \pm 0.35 \mathrm{~L} /\left[\mathrm{min} / \mathrm{m}^{2}\right] ; P=.03\right)$. There was no difference between the groups in the use of aortic crossclamp with cardioplegia; however, the duration of aortic crossclamping was significantly higher in patients who required $\mathrm{pRBC}$ transfusion ( $52 \pm 30$ vs $40 \pm 31$ minutes; $P<.001)$. Patients who did not require a pRBC transfusion were significantly less likely to have had DHCA $(5.3 \%$ vs $36.4 \% ; P<.001)$, and if DHCA was used, it was used for a shorter median duration (21 vs 33 minutes; $P=.005$ ).

\section{Association With Other Outcomes}

We also examined the relationship between requiring pRBC transfusion and total hospital length of stay and mortality (Table 1). Patients who did not receive pRBC transfusion had a significantly shorter total hospital length of stay with a median hospital stay of 4.8 days versus 7.5 days $(P<.001)$. Similarly, fewer patients who had not received pRBC transfusion died during the postoperative hospitalization $(0.4 \%$ vs $4.5 \% ; P=.001)$.

\section{Univariate Regression Analysis}

To examine which factors were potentially associated with the need for $\mathrm{pRBC}$ transfusion, a univariate logistic regression was performed on all candidate factors, as shown in Table 2. Because so few patients were classified in RACHS- 1 categories 4,5 , an 6 , and their overall risk appeared similar, these 3 categories were collapsed into 
TABLE 2. Univariate analysis of risk factors for requirement of packed red blood cell transfusion

\begin{tabular}{|c|c|c|c|}
\hline Variable & $\begin{array}{l}\text { Unadjusted } \\
\text { odds ratio }\end{array}$ & $\begin{array}{c}\text { 95\% Confidence } \\
\text { interval }\end{array}$ & $\begin{array}{c}P \\
\text { value }\end{array}$ \\
\hline $\begin{array}{l}\text { Prime volume (as indexed } \\
\text { to } \mathrm{BSA}, \mathrm{mL} / \mathrm{m}^{2} \text { ) }\end{array}$ & 1.007 & $1.006-1.008$ & $<.001$ \\
\hline Age at surgery (y) & 0.765 & $0.744-0.788$ & $<.001$ \\
\hline Surgeon & & & $<.001$ \\
\hline \multicolumn{4}{|l|}{ RACHS-1 category } \\
\hline 1 & 1 & Reference & - \\
\hline 2 & 10.464 & $7.024-15.588$ & $<.001$ \\
\hline 3 & 6.243 & $4.288-9.088$ & $<.001$ \\
\hline 4,5 , or 6 & 94.967 & $33.724-267.423$ & $<.001$ \\
\hline $\begin{array}{l}\text { Preoperative hemoglobin } \\
\qquad(\mathrm{g} / \mathrm{dL})\end{array}$ & 0.869 & $0.823-0.918$ & $<.001$ \\
\hline Previous cardiac surgery & 0.992 & $0.75-1.313$ & .958 \\
\hline $\begin{array}{l}\text { Prior cardiac surgery with } \\
\text { CPB }\end{array}$ & 0.946 & $0.709-1.264$ & .709 \\
\hline CPB time (min) & 1.015 & $1.012-1.019$ & $<.001$ \\
\hline Aortic crossclamp use & 1.031 & $0.708-1.501$ & .873 \\
\hline Aortic crossclamp time (min) & 1.018 & $1.012-1.025$ & $<.001$ \\
\hline DHCA use & 10.303 & $5.967-17.789$ & $<.001$ \\
\hline DHCA time $(\min )$ & 1.045 & $1.008-1.083$ & .017 \\
\hline $\begin{array}{l}\text { Minimal core body } \\
\text { temperature }\left({ }^{\circ} \mathrm{C}\right)\end{array}$ & 0.832 & $0.804-0.86$ & $<.001$ \\
\hline $\begin{array}{l}\text { Maximum flow (as indexed } \\
\text { to BSA, } \mathrm{L} /\left[\mathrm{min} / \mathrm{m}^{2}\right] \text { ) }\end{array}$ & 2.029 & $1.397-2.947$ & $<.001$ \\
\hline
\end{tabular}

a single category. Furthermore, patients whose surgery was unclassifiable under the RACHS- 1 method were not included in that analysis or in any subsequent analyses with the RACHS-1 variable, decreasing the total population to 2136 .

\section{Multivariable Regression Analysis}

A multivariable model $(n=2087)$ was constructed, examining all candidate variables identified from the univariate model. Indexed prime volume (as the primary variable of interest) and the categoric variable of surgeon were placed in the model a priori. Variables were removed from the model if after addition they were nonsignificant $(P>.05)$ and if their addition had no effect on the estimates for the other variables in the model. This resulted in the final multivariate model shown in Table 3. In the final model, RACHS-1 category was an independent predictor of pRBC transfusion, with higher odds of requiring pRBC transfusion in the higher RACHS-1 risk categories (Table 3). Both core body temperature and preoperative hemoglobin remained as independent risk factors, and their presence significantly affected the coefficient values for the RACHS-1 and surgeon variables; as such, both are included in the final model.

After controlling for surgeon, minimal core body temperature, preoperative hemoglobin, and RACHS-1 category,
TABLE 3. Final multivariable model of risk factors for requiring packed red blood cell transfusion after adjustment for operating surgeon

\begin{tabular}{lccc}
\hline Variable & $\begin{array}{c}\text { Adjusted } \\
\text { odds ratio }\end{array}$ & $\begin{array}{c}\mathbf{9 5} \% \text { Confidence } \\
\text { interval }\end{array}$ & $\begin{array}{c}\boldsymbol{P} \\
\text { value }\end{array}$ \\
\hline $\begin{array}{l}\text { Prime volume }(\text { as indexed } \\
\left.\text { to BSA, } \mathrm{mL} / \mathrm{m}^{2}\right)\end{array}$ & 1.006 & $1.005-1.007$ & $<.001$ \\
RACHS-1 category & & & \\
1 & 1 & Reference & - \\
2 & 5.195 & $3.109-8.680$ & $<.001$ \\
3 & 3.927 & $2.315-6.662$ & $<.001$ \\
4,5 , or 6 & 6.995 & $2.075-23.577$ & .002 \\
Minimal core body & 0.87 & $0.833-0.908$ & $<.001$ \\
temperature $\left({ }^{\circ} \mathrm{C}\right)$ & & & $<.001$ \\
Preoperative hemoglobin & 0.811 & $0.749-0.877$ & \\
$\quad(\mathrm{~g} / \mathrm{dL})$ & & & \\
BSA, Body surface area; RACHS- 1, Risk Adjustment for Congenital Heart Surgery 1.
\end{tabular}

indexed CPB prime volume remained a significant independent predictor of the need for $\mathrm{pRBC}$ transfusion, with an odds ratio of 1.006 (95\% confidence interval, $1.005-1.007)$, or a $0.6 \%$ increased odds of requiring $\mathrm{pRBC}$ transfusion for every increase of $1 \mathrm{~mL} / \mathrm{m}^{2}$ in CPB prime volume. To place this risk estimate in clinically relevant terms, the model was rerun to examine a $10-\mathrm{mL}$ change in absolute prime volume for patients at the 10th, 50th, and 90th percentiles of BSA in our study population $(0.2,0.34$, and $0.9 \mathrm{~m}^{2}$ ). For patients at these sizes, a $10-\mathrm{mL}$ change in absolute CPB prime volume resulted in indexed prime volume changes of 50,29 , and $11 \mathrm{~mL} / \mathrm{m}^{2}$, respectively. The odds ratios for these changes were 1.35, 1.19, and 1.07; that is, a $10-\mathrm{mL}$ change in absolute prime volume increased the odds of requiring pRBC transfusion by $35 \%$ in a patient with a BSA of $0.2 \mathrm{~m}^{2}$, by $19 \%$ in a patient with a BSA of $0.34 \mathrm{~m}^{2}$, and by $7 \%$ in a patient with a BSA of $0.9 \mathrm{~m}^{2}$. Figure 1 illustrates the relationship between the odds of requiring $\mathrm{pRBC}$ transfusion and absolute $\mathrm{CPB}$ circuit prime volume for different patient sizes. As shown, the odds of requiring pRBC transfusion increase 2-fold at increases of 25 $\mathrm{mL}$ for a BSA of $0.2 \mathrm{~m}^{2}, 60 \mathrm{~mL}$ for a BSA of $0.5 \mathrm{~m}^{2}, 120 \mathrm{~mL}$ for a BSA of $1 \mathrm{~m}^{2}$, and $175 \mathrm{~mL}$ for a BSA of $1.5 \mathrm{~m}^{2}$.

\section{DISCUSSION}

In this study of more than 2000 consecutive pediatric patients undergoing cardiac surgery with $\mathrm{CPB}$, we found that $\mathrm{CPB}$ prime volume (as indexed to BSA) was a significant independent predictor of requirement of pRBC transfusion in the perioperative period, even after controlling for surgeon, operative risk, preoperative hemoglobin value, and minimal core temperature during $\mathrm{CPB}$, which also serve as independent risk factors themselves. Certainly the morbidities associated with blood transfusions in this population have been well established; however, this is the first study to identify the potentially modifiable variable of 


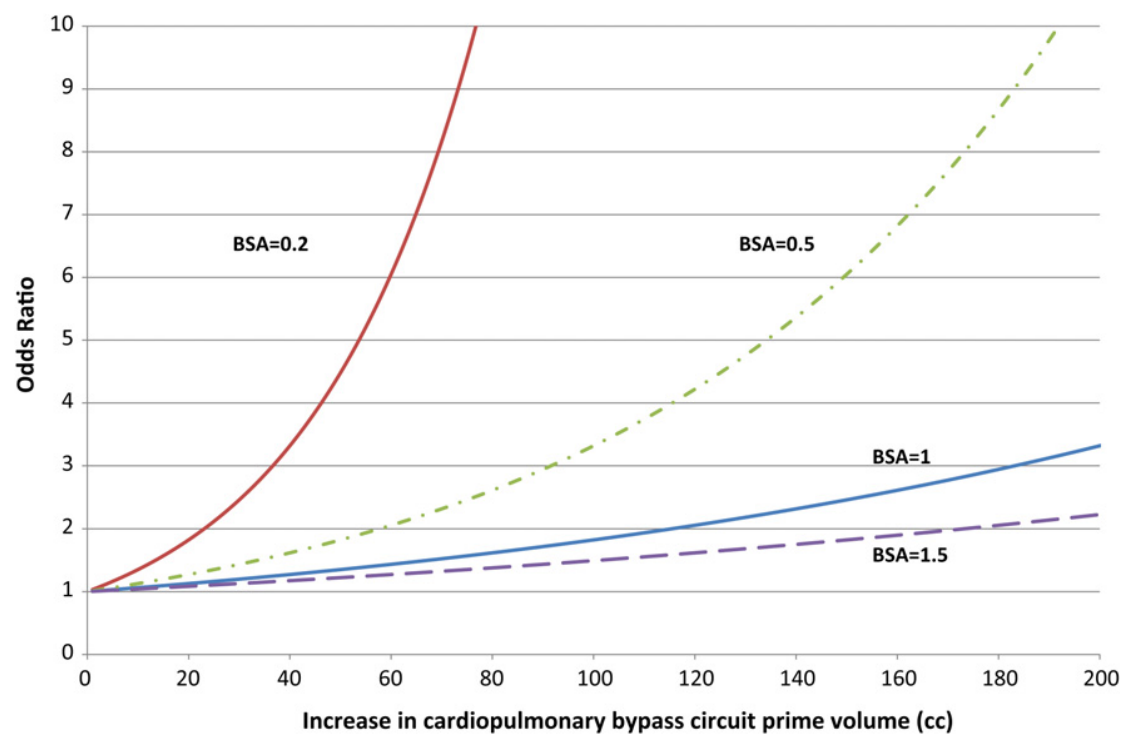

FIGURE 1. Curves representing the change in odds of receiving a blood transfusion in relation to an absolute change in cardiopulmonary bypass circuit prime volume for patients with body surface areas $(B S A)$ of $0.2,0.5,1$, and $1.5 \mathrm{~m}^{2}$. Note that a doublings of the odds ratio occur at 20,60, 120, and $175 \mathrm{~mL}$, respectively, for these different sizes of patients.

CPB circuit priming volume as an independent risk factor for blood transfusion after pediatric cardiac surgery. Although the effect of indexed prime volume at first appears modest, we have demonstrated that even a decrease of 10 or $20 \mathrm{~mL}$ in circuit prime volume can have a profound effect on small children. Despite this robust finding, however, there are limitations to the current study that should be explored.

The sample population of this study was taken from consecutive pediatric cardiac surgical patients at a single largevolume institution. One of the strengths of this study is the uniformity of treatment, because there were no significant institutional changes to perioperative management during the study period with regard to blood transfusion. During the 5-year study period, however, there were a total of 4 surgeons who operated at our institution, and certainly it could be argued that surgical operative technique influences the need for transfusion. Furthermore, the surgical experience was widely varied among the 4 surgeons, from less than 5 years to more than 20 years. Even after controlling for this variation, however, the odds of requiring transfusion as related to CPB prime volume remained remarkably steady and significant. In addition to surgeon variability, our population may not be representative of all surgical programs. Because of the high proportion of high-risk surgical procedures ( $45 \%$ RACHS -1 category 3 or greater, and only $7 \%$ RACHS- 1 category 1 ), it is unclear that similar findings would be found in a surgical population consisting of mostly low-risk procedures, probably because the overall risk of transfusion would be much lower to begin with.

Perhaps the most important limitation of this study is the fact that it arises from observational data. Although a prospective study with defined criteria for transfusion would be ideal, we have minimized any biases by using prospectively collected surgical data, which significantly limited the amount of missing data and the potential for recall or information biases. In fact, only $4 \%$ of patients identified as meeting inclusion criteria had missing data, resulting in exclusion from the analysis.

Our institution does not have a single standard target hemoglobin concentration during (or after) CPB. Typically, an estimated postdilutional hematocrit less than $25 \%$ will trigger the addition of pRBCs to the prime. In some younger or cyanotic patients, however, pRBCs are added to maintain a postdilutional hematocrit of at least $30 \%$, or even $35 \%$. As such, subjects within the study may have had different target hemoglobin concentrations, as determined by the clinical team. Because of the observational nature of this study, it is impossible to determine what threshold was used for transfusion in each case because there are many factors that may have caused a patient to receive blood products in the operating room, including, but not limited to the clinical judgment of the surgeon, anesthesiologist, and any other provider involved in the care of the patient. It is impossible to control for all of these factors, but it is unlikely that the combination of these factors would correlate directly with the indexed CPB circuit prime volume. Other factors, such as patient age, preoperative hemoglobin value, or length of CPB support may also influence the clinical decision to transfuse; however, these factors were examined and controlled for in the analysis and did not have any effect on the risk of transfusion as it related to indexed CPB prime volume. Furthermore, the interaction between age and indexed prime volume was examined and determined to be 
nonsignificant. Finally, it is possible that the clinical perfusionist who constructs the CPB circuit may influence the transfusion practice in the operating room. There were numerous perfusionists involved in these cases, however, and the incremental nature of the relationship between indexed prime volume and the need for transfusion makes this a less likely confounding factor. Furthermore, bypass circuit volumes and prime composition were standard among perfusionists. Our center has 8 standard circuits, ranging in prime volume from 180 to $1100 \mathrm{~mL}$. The choice of circuit is typically made on the basis of the required circuit flow rate, as illustrated in Table 4.

It is important to note that our standard of care for pediatric patients on CPB does not include the routine use of modified ultrafiltration (MUF), which has been proposed as a mechanism for decreasing the need for transfusion, especially in smaller patients and those with long CPB times. ${ }^{4}$ How indexed CPB prime volume affects the need for transfusion in centers that routinely use MUF is unclear; however, we believe that minimizing prime volume and avoiding the need for MUF is a superior approach to the high-risk and infant patient. It is the unique techniques of CPB circuit minimization that have allowed for successful surgical approaches in the smaller infants without the use of pRBC transfusions or MUF. Throughout the years, we have used a multitude of circuit modifications, including many that have been previously reported in the literature by other groups, such as remote pump heads, minimizing extraneous tubing, removing redundant circuits, and newer and smaller volume oxygenators. ${ }^{5,6}$

Despite the limitations, this study adds important new knowledge to the reasons that children undergoing cardiac surgery require blood transfusions. As the negative consequences of blood transfusions in this population become clearer, interventions aimed at decreasing the likelihood of requiring a blood transfusion will become more commonplace. Williams and colleagues ${ }^{7}$ evaluated factors that lead to transfusion requirements in 1999 and found that age at surgery was the most predictive of bleeding and the need for $\mathrm{pRBC}$ transfusion. This group also identified other risk factors, such as surgical complexity, length of DHCA, and minimal core temperature, similar to our results.

TABLE 4. Pump flow rates and prime volumes for the 8 standard circuits used during the study time frame

\begin{tabular}{lcc}
\hline Circuit & Desired flow $(\mathbf{L} / \mathbf{m i n})$ & Prime volume $(\mathbf{m L})$ \\
\hline 1 & $\leq 0.650$ & 180 \\
2 & $\leq 0.650$ & 220 \\
3 & $>0.650-1.2$ & 270 \\
4 & $>1.2-1.5$ & 375 \\
5 & $>1.5-1.9$ & 610 \\
6 & $>1.9-3.2$ & 640 \\
7 & $>3.2-5$ & 950 \\
8 & $>5$ & 1100 \\
\hline
\end{tabular}

Although our study did not identify age at surgery as an independent risk factor, it is likely that the indexed prime volume was higher in the younger patients; thus the effect of age seen in their study may actually have been mediated through prime volume. More recently Székely and associates ${ }^{8}$ looked at factors that influenced the need for transfusions of all blood products in an effort to adjust for these factors in associating transfusions with outcomes. Although not the primary aim of their study, they found weight at the time of surgery was the most predictive of the need for pRBC transfusion, even after adjustment for the need for preoperative mechanical ventilation, creatinine clearance, aortic crossclamp time, and intraoperative fluid balance. Similar to age, we hypothesize that the effect of weight at the time of surgery could also be mediated through indexed prime volume, making these results consistent with our study as well. Further supporting our findings is the inclusion of weight at the time of surgery as a risk factor for requiring transfusion in even some adult reports. ${ }^{9}$ Because most adult bypass circuits are of a standard volume, smaller patient weight results in higher indexed prime volumes, and these results could show the same mechanism as our pediatric study.

The effects of bypass prime volume on the risk of transfusion are magnified in smaller patients as exhibited in Figure 1. Thus even modest changes in the circuit composition can create real changes in transfusion risk. For example the use of a pediatric arterial filter (eg, Affinity Pediatric Arterial Filter; Medtronic Perfusion Systems, Brooklyn Park, Minn), instead of the adult version from the same manufacturer (eg, Affinity Arterial Filter; Medtronic Perfusion Systems) can decrease circuit prime volume by $30 \mathrm{~mL}$. We have used both filters successfully in circuits to support patients with a BSA range of 0.5 to $1.5 \mathrm{~m}^{2}$. During the 5-year study period, 580 patients with a BSA between 0.5 and $1.5 \mathrm{~m}^{2}$ underwent surgery at our institution. If all these patients had had the circuit prime volume decreased by the previously mentioned technique, after controlling for RACHS-1 category, preoperative hemoglobin, and minimal core body temperature, the average decrease in the odds of receiving a transfusion would be $22 \%$. This would have resulted in approximately 90 additional patients avoiding transfusion ( $15 \%$ of the total surgical population).

In summary, it appears that $\mathrm{CPB}$ circuit prime volume is a potentially modifiable risk factor for the need for blood transfusion in pediatric patients undergoing cardiac surgery with CPB. Dramatic changes in the risk of transfusion can occur with even modest changes to the absolute circuit prime volume, because the relationship is based on the patient's BSA as well. As little as a 20 -mL change in prime volume can effect a 2-fold increase or decrease in the risk of requiring a blood transfusion in an infant, and even a modest $150-\mathrm{mL}$ change in an adult-sized circuit can modify the patient's risk substantially. Although further study 
into the reasons that patients require transfusions is warranted, these results would seem to promote the concept of circuit miniaturization as an immediate way to decrease this risk.

We acknowledge Roger Vaughn, PhD, and Douglas Sproule, MD, MS, for their mentorship and advice with study design and statistical analysis, and Ms. Linfang Li and Ms. Alla Babina for their invaluable database support.

\section{References}

1. Kipps AK, Wypij D, Thiagarajan RR, Bacha EA, Newburger JW. Blood transfusion is associated with prolonged duration of mechanical ventilation in infants undergoing reparative cardiac surgery. Pediatr Crit Care Med. 2011;12:52-6.

2. Salvin JW, Scheurer MA, Laussen PC, Wypij D, Polito A, Bacha EA, et al. Blood transfusion after pediatric cardiac surgery is associated with prolonged hospital stay. Ann Thorac Surg. 2011;91:204-10.
3. Jenkins KJ, Gauvreau K, Newburger JW, Spray TL, Moller JH, Iezzoni LI. Consensus-based method for risk adjustment for surgery for congenital heart disease J Thorac Cardiovasc Surg. 2002;123:110-8.

4. Guzzetta NA. Benefits and risks of red blood cell transfusion in pediatric patients undergoing cardiac surgery. Pediatr Anesth. 2011;21:504-11.

5. Ando M, Takahashi Y, Suzuki N. Open heart surgery for small children without homologous blood transfusion by using remote pump head system. Ann Thorac Surg. 2004;78:1717-22.

6. Miyaji K, Kohira S, Miyamoto T, Nakashima K, Sato H, Ohara K, et al. Pediatric cardiac surgery without homologous blood transfusion, using a miniaturized bypass system in infants with lower body weight. $J$ Thorac Cardiovasc Surg. 2007; 134:284-9.

7. Williams GD, Bratton SL, Ramamoorthy CF. Factors associated with blood loss and blood product transfusions: a multivariate analysis in children after openheart surgery. Anesth Analg. 1999;89:57-64.

8. Székely A, Cserép Z, Sápi E, Breuer T, Nagy CA, Vargha P, et al. Risks and predictors of blood transfusion in pediatric patients undergoing open heart operations. Ann Thorac Surg. 2009;87:187-97.

9. Karkouti K, Cohen MM, McCluskey SA, Sher GD. A multivariable model for predicting the need for blood transfusion in patients undergoing first-time elective coronary bypass graft surgery. Transfusion. 2001;41:1193-203. 